ARTICLE

DOI: $10.1038 / s 41467-017-01009-1$

\title{
Arginine methylation catalyzed by PRMT1 is required for $B$ cell activation and differentiation
}

\author{
Simona Infantino 1,2,3, Amanda Light ${ }^{1,2}$, Kristy O'Donnell 1,2,3, Vanessa Bryant ${ }^{1,2}$, Danielle T. Avery ${ }^{4}$, \\ Michael Elliott ${ }^{5,6}$, Stuart G. Tangye (iD) ${ }^{4,7}$, Gabrielle Belz (1) ${ }^{1,2}$, Fabienne Mackay ${ }^{8}$, Stephane Richard ${ }^{9}$ \\ \& David Tarlinton $1,2,3$
}

\begin{abstract}
Arginine methylation catalyzed by protein arginine methyltransferases (PRMT) is a common post-translational modification in mammalian cells, regulating many important functions including cell signalling, proliferation and differentiation. Here we show the role of PRMT1 in B-cell activation and differentiation. PRMT1 expression and activity in human and mouse peripheral $B$ cells increases in response to in vitro or in vivo activation. Deletion of the Prmt1 gene in mature $B$ cells establishes that although the frequency and phenotype of peripheral $B$ cell subsets seem unaffected, immune responses to T-cell-dependent and -independent antigens are substantially reduced. In vitro activation of Prmt1-deficient B cells with a variety of mitogens results in diminished proliferation, differentiation and survival, effects that are correlated with altered signal transduction from the B cell receptor. Thus PRMT1 activity in B cells is required for correct execution of multiple processes that in turn are necessary for humoral immunity.
\end{abstract}

\footnotetext{
${ }^{1}$ Walter and Eliza Hall Institute of Medical Research, Parkville, Victoria 3052, Australia. ${ }^{2}$ Department of Medical Biology, University of Melbourne, Parkville, Victoria 3010, Australia. ${ }^{3}$ Department of Immunology and Pathology, Monash University, Melbourne, Victoria 3004, Australia. ${ }^{4}$ Immunology Division, Garvan Institute of Medical Research, Darlinghurst, NSW 2010, Australia. ${ }^{5}$ Sydney Medical School, University of Sydney, Sydney, NSW 2006, Australia. ${ }^{6}$ Chris O'Brien Lifehouse Cancer Centre, Royal Prince Alfred Hospital, Sydney, NSW 2050, Australia. ${ }^{7}$ St Vincent's Clinical School, Faculty of Medicine, University of NSW, Darlinghurst, NSW 2010, Australia. ${ }^{8}$ Department of Microbiology and Immunology, University of Melbourne, Parkville, Victoria 3010, Australia. ${ }^{9}$ Lady Davis Institute for Medical Research, McGill University, 3755 Cote Ste-Catherine Road, Montreal, Quebec, Canada H3T 1 E2. Correspondence and requests for materials should be addressed to S.I. (email: simona.infantino@monash.edu) or to D.T. (email: david.tarlinton@monash.edu)
} 
M ethylation of arginine is the most abundant type of protein methylation in mammalian cells and is a major modulator of protein function ${ }^{1}$. The three identified types of modified arginine are monomethylated arginine (MMA), asymmetric dimethylated arginine (ADMA) and symmetric dimethylated arginine (SDMA), all catalyzed by one of the nine known protein arginine methyltransferases $(\mathrm{PRMT})^{1-3}$. ADMA formation is catalyzed by type I PRMTs (comprising PRMT1, 2, 3, 4, 6 and 8), SDMA by type II (PRMT5) and MMA by type III (PRMT7) ${ }^{1}$. The importance of the modifications catalyzed by these enzymes is indicated by embryonic lethality of PRMT1-deficient and PRMT5-deficient mice ${ }^{4,5}$ and by the severe phenotype of PRMT2, PRMT3, PRMT4 and PRMT6-deficient mice $^{6-9}$

PRMT1 is the major arginine methyltransferase active in mammalian cells and is required for normal embryogenesis, cell cycle progression, cell viability, and signal transduction ${ }^{1,2,} 6,10$. PRMT1 methylates histones, RNA-binding proteins (RBPs), cell cycle proteins and proteins involved in regulating gene transcription, including high-mobility group proteins (HMGA) and runt-related transcription factor 1 (RUNX1) ${ }^{1,2}$. PRMT1 is also an active component of signal transduction pathways including those from the B-cell receptor (BCR), T-cell receptor (TCR), nerve growth factor receptor, type 1 interferon receptor, and the pathway involving NF-AT ${ }^{11-16}$. PRMT1 is also known to directly regulate the activity of forkhead box protein $\mathrm{O} 1(\mathrm{FOXO} 1)^{18}$ and Bcl-2-associated death promoter $(\mathrm{BAD})^{17}$, proteins associated with cell viability. In these examples, the motif $\mathrm{RxRxxS} / \mathrm{T}$ recognized by protein kinase $\mathrm{B}$ (PKB) and present in both FOXO1 and BAD, overlaps with sites recognized by PRMT1, leading to competition in which methylation by PRMT1 inhibits phosphorylation by $\mathrm{PKB}$, thereby prolonging the localization of FOXO1 in the nucleus in one case and inhibiting the proapoptotic activity of BAD in the other ${ }^{17}, 18$. Clearly, arginine methylation catalyzed by PRMT1 is crucial to a multitude of pathways although the regulation of its activity is unclear in the majority of cases.

We described previously a PRMT1 target motif within the Ig- $\alpha$ signalling component of the $\mathrm{BCR}^{14}$. This evolutionarily conserved arginine is proximal to the immunoreceptor tyrosine activation motif (ITAM) of Ig- $\alpha$, is methylated directly by PRMT1 in immature $\mathrm{B}$ cells, and regulates the activation and differentiation of these cells following BCR ligation ${ }^{14}$. Interestingly, arginine methylation of Ig- $\alpha$ in immature B cells is transiently diminished following BCR ligation, indicating this methylation could be a controlled event and therefore, arginine methylation could contribute to the regulation of B-cell activation in physiological settings ${ }^{14}$. To investigate the possible involvement of PRMT1 in Bcell differentiation further, we undertook an analysis of immune function in mice with Prmt1 deleted specifically in mature B cells. This analysis revealed the post-translational modification of proteins catalysed by PRMT1 to be a regulated event, and to be essential for normal proliferation, differentiation and survival of activated $\mathrm{B}$ cells in vitro and for normal antibody responses to antigen in vivo.

\section{Results}

PRMT1 is dispensable in mature $B$ cells. We analyzed the function of PRMT1 in mature B cells by generating mice in which Prmt1 was deleted only in the periphery, which also circumvented the congenital lethality of its deficiency ${ }^{4}, 19$. This was done by crossing Prmt $1^{f / f}$ mice with mice in which Cre recombinase was expressed under the control of $C D 23$ regulatory elements ${ }^{20}$, thereby initiating deletion at the T2 stage of B-cell development to produce a peripheral B-cell compartment that was Prmt1 a
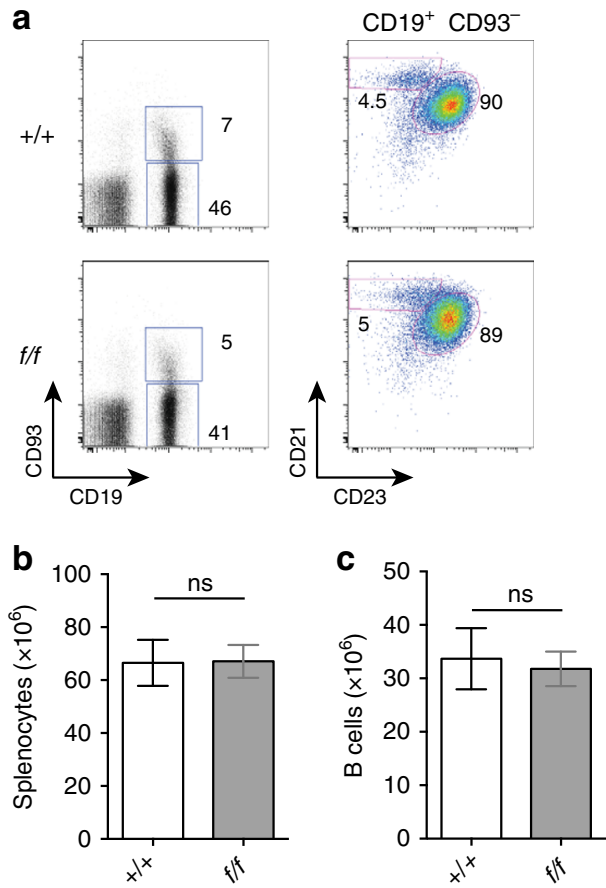

d
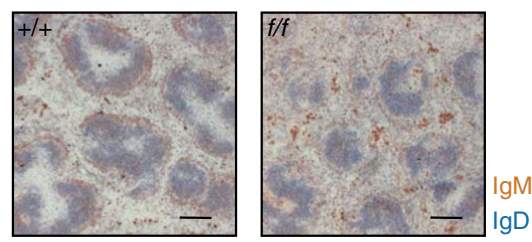

Fig. 1 Intact $\mathrm{CD} 23^{+}$B-cell compartment despite deletion of Prmt1. a Representative flow cytometry plots examining the frequency of mature $\left(\mathrm{CD} 19^{+} \mathrm{CD}^{-} 3^{-}\right)$, immature $\left(\mathrm{CD} 19^{+} \mathrm{CD}^{+} 3^{+}\right)$, follicular $\left(\mathrm{CD} 19^{+} \mathrm{CD} 93^{-}\right.$ $\left.\mathrm{CD} 23^{+} \mathrm{CD} 21^{+}\right)$and $\mathrm{MZ}\left(\mathrm{CD} 19^{+} \mathrm{CD} 93^{-} \mathrm{CD} 23^{-} \mathrm{CD} 21^{+}\right) \mathrm{B}$ cells in the spleen of control $(+/+)$ and $\mathrm{Prmt}^{f / f} \mathrm{CD} 23 \mathrm{Cre}(f / f)$ mice. Numbers indicate percentage of the displayed events. b, c Number of splenocytes and B cells are indicated. $\mathbf{d}$ Representative immunohistochemical staining of frozen sections from spleens of control $(+/+)$ and $P r m t 7^{f / f} C D 23 C r e(f / f)$ naive mice with scale bars indicating $100 \mu \mathrm{m}$. All data are representative of three independent experiments and $n=10$ mice. Statistical significances were determined using Student's $t$-test; ns = not significant. Mean and s.e.m. in $\mathbf{b}$ and c. Flow cytometry gating strategies for this figure are shown in Supplementary Fig. 6

deficient. Analysis of B-cell development in the spleens of these Prmt $1^{f f f} \mathrm{CD} 23 \mathrm{Cre}$ mice revealed no abnormalities in B-cell number, phenotype or distribution (Fig. 1). This was true for both immature and mature B cells, distinguished by CD93 expression, and for marginal zone and follicular B cells, resolved by $\mathrm{CD} 21$ and CD23 expression (Fig. 1a-c). The localization of B cells in the splenic white pulp also was unaffected by loss of PRMT1 (Fig. 1d). Thus, despite the absolute requirement for PRMT1 in embryogenesis $^{4}$, it was not required for the appearance or maintenance of B-cell subsets in the periphery.

B-cell activation increases PRMT activity. We next examined the amount of PRMT1 in B cells, both resting and after activation. $B$ cells were purified from the spleens of control and Prmt $1^{f / f}$ CD23Cre mice and the amount of PRMT1 assessed by western blot before and after stimulation with CD40L in the presence of interleukins (IL) 4 and 5. PRMT1 was detected in unstimulated control B cells and in increased amounts following activation 


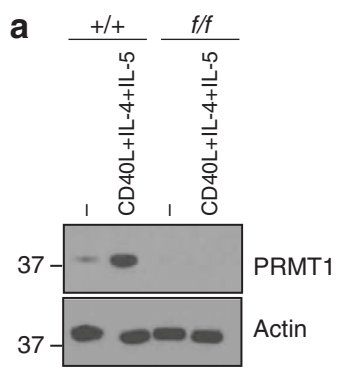

b
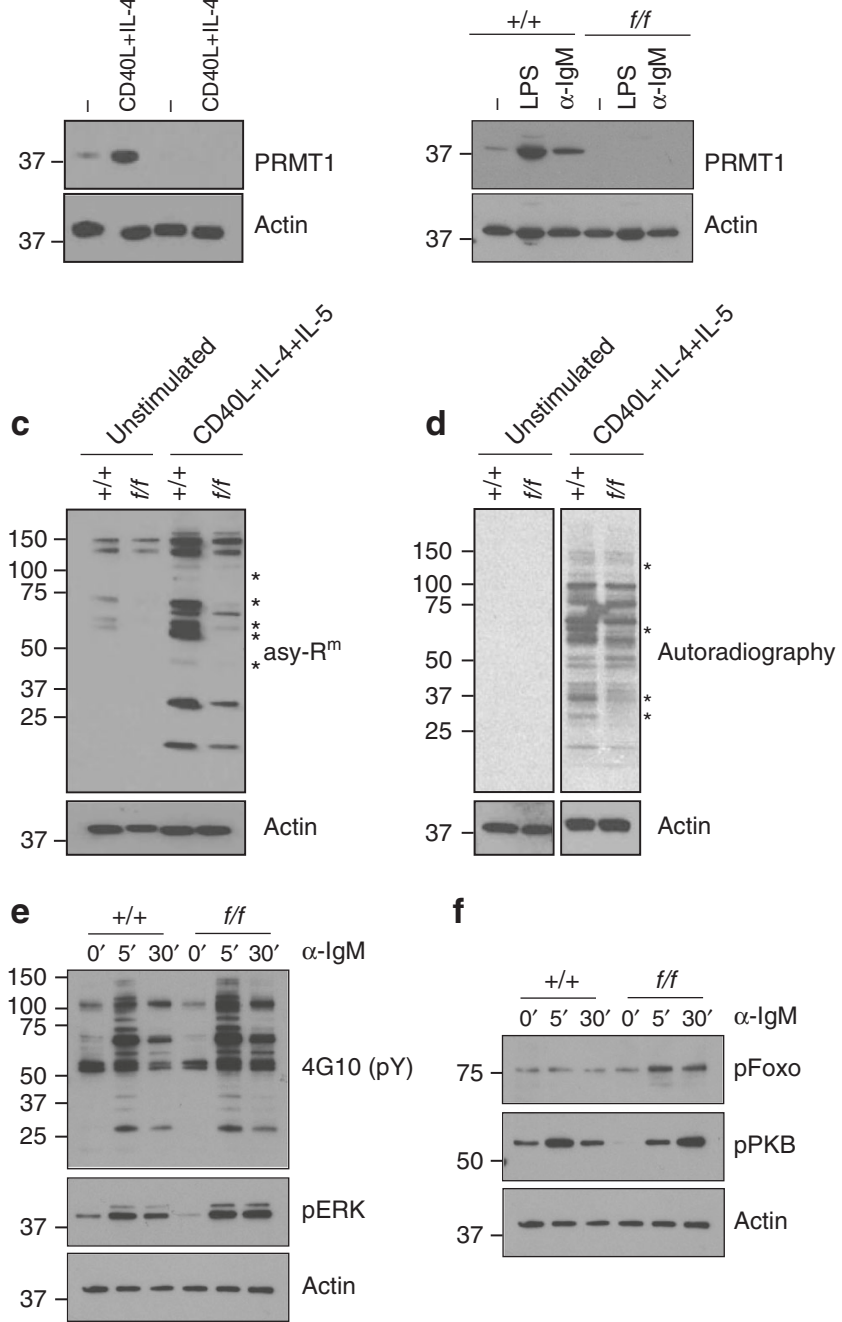

f

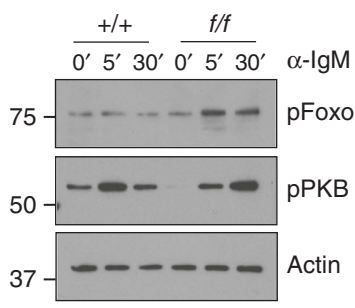

Fig. 2 Increased PRMT1 and arginine methylated proteins in activated B cells. Immunoblot analysis of control $(+/+)$ and Prmt1-deficient $(f / f)$ splenic $B$ cells for PRMT1 induction after a 2 days stimulation with CD4OL and IL-4 and IL-5 or $\mathbf{b} 2$ days stimulation with LPS or F $\left(a b^{\prime}\right)_{2}$ anti-lgM as indicated and compared to actin loading control. c Distribution of asymmetric-dimethylated arginine (asy- $\mathrm{R}^{\mathrm{m}}$ ) containing proteins in unstimulated and 2 day CD4OL + IL-4 + IL-5 stimulated control (+/+) and Prmt7-deficient $(f / f)$ splenic $B$ cells, using specific antibody and compared to actin loading control. d Ex vivo methylation assay. Unstimulated (left panel) or day $2 \mathrm{CD} 4 \mathrm{OL}+\mathrm{IL}-4+\mathrm{IL}-5$ activated (right panel) control $(+/+)$ and Prmt1-deficient $(f / f)$ B cells were grown for $3 \mathrm{~h}$ in the presence of L[methyl-3H]methionine and protein synthesis inhibitors. Autoradiography of lysates reveals methylated proteins. Asterisks in $\mathbf{c}$, $\mathbf{d}$ indicate proteins that are differentially methylated between control and Prmt1-deficient $B$ cells. e, $\mathbf{f} B$ cells were activated with $F\left(a b^{\prime}\right)_{2}$ anti-lgM for the indicated time points. Western blot analysis of the whole-cell lysates shows the level of phospho-tyrosine (4G10), pERK (T202/Y204), e pFoxo1(pS256) and pPKB (S473) f. Actin is used as a loading control. Similar results were obtained in three independent experiments in which each sample was derived from a pool of three mice. Uncropped images of blots are presented in Supplementary Fig. 5
(Fig. 2a). Amounts of PRMT1 increased after stimulating control $\mathrm{B}$ cells with either lipopolysaccharide (LPS) or $\mathrm{F}\left(\mathrm{ab}^{\prime}\right)_{2}$ anti-IgM, albeit to a greater extent with LPS (Fig. 2b). As expected, PRMT1 was not detected in Prmt1 flf CD23Cre B cells (Fig. 2a, b). The presence of PRMT1 in control B cells and its increase following activation suggested that PRMT1 activity, and thus the distribution of proteins containing asymmetrically dimethylated arginine, would also change following B-cell stimulation. We assessed PRMT1 activity in resting and activated B cells by two methods. First, total cell lysates from resting and activated, control and Prmt ${ }^{f / f}$ CD23Cre B cells were separated by gel electrophoresis and probed for the presence of proteins containing asymmetric dimethylated arginines using a specific antibody. In resting, control B cells, several bands were revealed, indicating constitutive arginine methylation of a subset of proteins (Fig. 2c). Despite the absence of PRMT1, asymmetrically dimethylated proteins were detected in lysate from unstimulated Prmt $1^{f / f}$ CD23Cre B cells, but at a frequency and intensity that was less than in control B-cell samples (Fig. 2c), and presumably reflected the activity of other type I PRMTs in these cells. The intensity of asymmetric dimethylated arginine-containing protein bands increased in control B cells following activation with CD40L, coincident with the increased amounts of PRMT1 (Fig. 2a, c). Some bands corresponded in molecular weight to those present in the unstimulated control B-cell sample, but the intensity was increased and new bands were visible (Fig. 2c). The number and intensity of arginine methylated protein bands also increased in CD40L-stimulated Prmt1-deficient B cells relative to their unstimulated sample, but again their frequency and intensity were less than in equivalently treated control samples (Fig. 2c). Importantly, unique bands were detected in the stimulated control samples that were not present in the equivalent Prmt1-deficient sample, indicating unique PRMT1 substrates in B cells. The second approach assessed ongoing or active methylation by culturing $\mathrm{B}$ cells in the presence of both radioactive L-[methyl-3H] methionine and protein synthesis inhibitors. This assay did not detect ongoing methylation in unstimulated B cells from either Prmt ${ }^{f / f}$ CD23Cre or control animals, but the activity increased significantly in both genotypes following stimulation (Fig. 2d). Again, the extent and intensity of labelling differed between control and Prmt1-deficient B cells, reflecting increased methyltransferase activity in the control B-cell sample. Collectively these results indicate that PRMT1 is a major asymmetric dimethytransferase in B cells, that its activity increases following stimulation and that it has unique substrates in B cells.

In light of the role PRMT1 activity has in regulating signalling events downstream of the BCR in immature $B$ cells ${ }^{14}$, we examined the consequences of PRMT1 deficiency on signal transduction following BCR ligation on mature, naive B cells. Control and Prmt1-deficient B cells were stimulated with $\mathrm{F}\left(\mathrm{ab}^{\prime}\right)_{2}$ anti-IgM, then lysed after 0,5 or $30 \mathrm{~min}$ and the distribution of tyrosine phosphorylated proteins determined (Fig. 2e). At time zero, the few tyrosine phosphorylated protein bands were distributed similarly in both B-cell samples. After $5 \mathrm{~min}$ stimulation, the intensity and number of such bands had increased substantially in both Prmt1-deficient and control B-cell samples, again with similar distributions. At 30 min post stimulation, the intensity of bands in both samples was reduced from their $5 \mathrm{~min}$ peaks, however the reduction was less in Prmt1-deficient B cells than in controls, resulting in a relative hyper-phosphorylation in the absence of PRMT1 (Fig. 2e). Interestingly we also found increased phosphorylation of ERK1/2, FOXO1 and PKB in equivalently anti-IgM stimulated Prmt1deficient $B$ cells (Fig. 2e, f). These results revealed activationinduced increases in PRMT1 activity under a variety of conditions and an apparent prolongation of signalling from the 
a

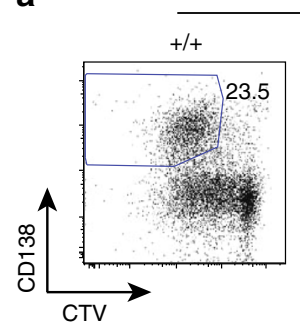

Day 4
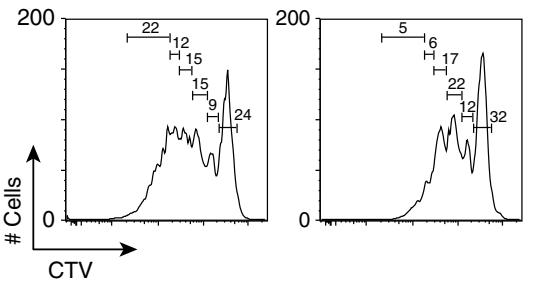

Day 4
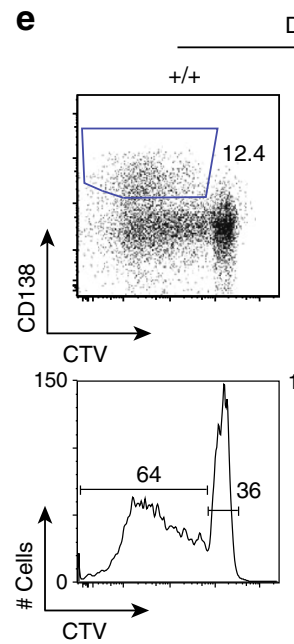

b

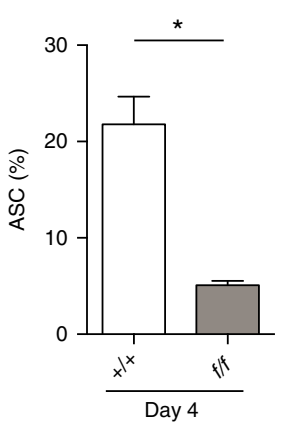

f

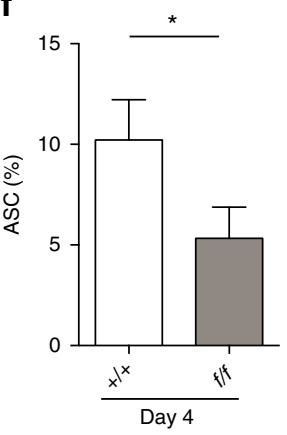

C

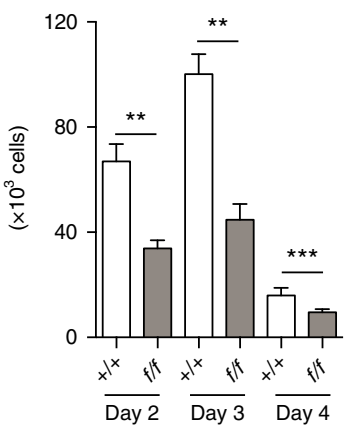

d

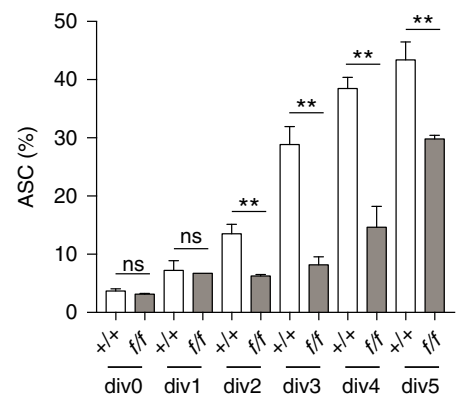

g

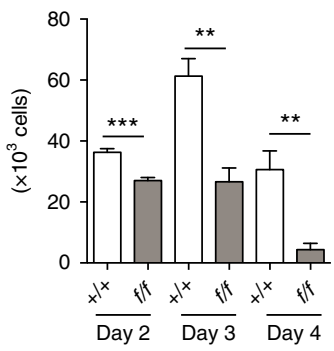

Fig. 3 Defective response of Prmt1-deficient B cells to in vitro stimulation. Control $(+/+)$ and Prmt $t^{f / f} \mathrm{CD} 23 \mathrm{Cre}(f / f)$ splenic B cells, labelled with CTV, were activated with a-d CD $40 \mathrm{~L}+\mathrm{IL}-4+\mathrm{IL}-5$ or $\mathbf{e}-\mathbf{g}$ LPS $\left(25 \mu \mathrm{g} \mathrm{ml} \mathrm{l}^{-1}\right)$ for the indicated times. a, e Cultured cells were monitored for ASC differentiation with antiCD138 antibody (top panels) and extent of cell division with CTV dilution (bottom panels). Percentages are the proportion of viable cells within indicated regions. b, $\mathbf{f}$ Frequency of live, CD138 ${ }^{+}$ASC at 4 days after activation. c, $\mathbf{g}$ Number of viable cells in cultures after stimulation for the indicated times. $\mathbf{d}$ Frequency of $\mathrm{CD} 138^{+}$cells within the indicated cell divisions of $\mathrm{CD} 4 \mathrm{OL}+\mathrm{IL}-4+\mathrm{IL}-5$ stimulated control $(+/+)$ and Prmt $7^{f / f} \mathrm{CD} 23 \mathrm{Cre}(f / f)$ splenic B cells at day 4. ${ }^{\star} P \leq 0.05{ }^{\star \star} P \leq 0.01,{ }^{\star \star \star} P \leq 0.001$ (unpaired $t$-test). One representative experiment of three, with three biological replicates, is shown. (Mean and $\mathrm{s}$. e.m in b-d, f, g). Flow cytometry gating strategies for this figure are shown in Supplementary Fig. 7

BCR in the absence of PRMT1. We also examined CD19+ $\mathrm{B}$ cells isolated from human peripheral blood for PRMT1 amounts before and after CD40L + IL-4 activation and found the amount also increased following stimulation (Supplementary Fig. 1a).

PRMT1 deficiency affects B-cell proliferation and differentiation. The increased amount of PRMT1 in B cells after stimulation suggested a possible role for protein arginine methylation in B-cell activation. To assess this, we labelled control and Prmt1deficient mouse B cells with the division tracking dye, CTV, and then cultured the cells with CD40L, IL-4 and IL-5. The extent of B-cell proliferation and differentiation were compared after 4 days using, respectively, the distribution of cell divisions and the frequency of antibody secreting cell (ASC) as indicated by CD138 expression $^{21}$. This analysis revealed reduced proliferation and differentiation in the Prmt1 ${ }^{f / f}$ CD23Cre B-cell cultures (Fig. 3a, b). The impact of Prmt1 deficiency on proliferation was apparent throughout the culture, as assessed by counting the number of $\mathrm{B}$ cells on successive days (Fig. 3c). To separate effects on proliferation from differentiation, which are intimately linked ${ }^{22}$, we assessed the division profiles of control and Prmt1-deficient B cells after 4 days stimulation with CD40L, IL- 4 and IL-5 for the relative frequency of $\mathrm{CD}_{138^{+}}$cells, thereby normalizing for proliferation (Fig. 3d). While this revealed division-dependent increases in differentiation in both control and Prmt1-deficient B-cell cultures, there was significantly less differentiation per division in the latter. Equivalent experiments using LPS stimulation (Fig. $3 \mathrm{e}-\mathrm{g}$ ) also revealed significantly less proliferation and differentiation in Prmt1-deficient B cells compared to controls, which was apparent again over the course of the culture (Fig. 3e-g). Thus Prmt1 deficiency affected both B-cell proliferation and differentiation, although the effect on the former appeared to be more marked.

Lymphocyte activation induces metabolic changes that have profound effects on cell proliferation and differentiation ${ }^{23}$. In $\mathrm{B}$ cells, for example, metabolic reprogramming is required for antibody production ${ }^{24}$. Given the requirement for PRMT1 in normal B-cell activation, next we compared the metabolic pathways utilized in control and Prmt1-deficient B cells. This 
a

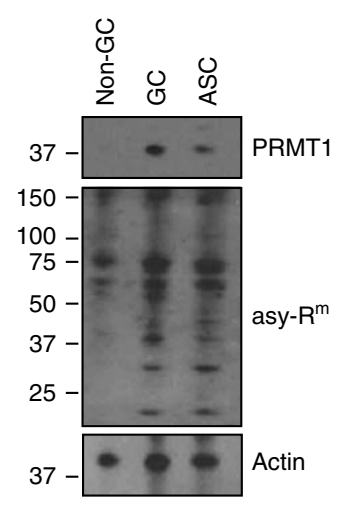

b

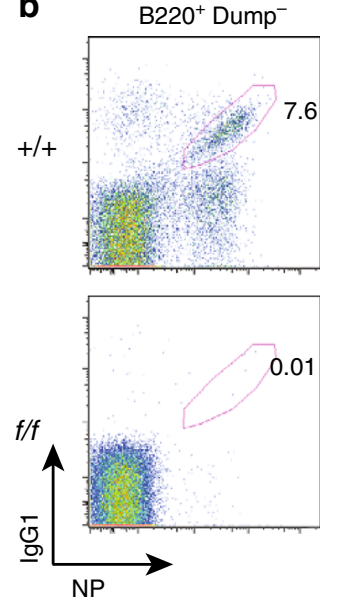

C
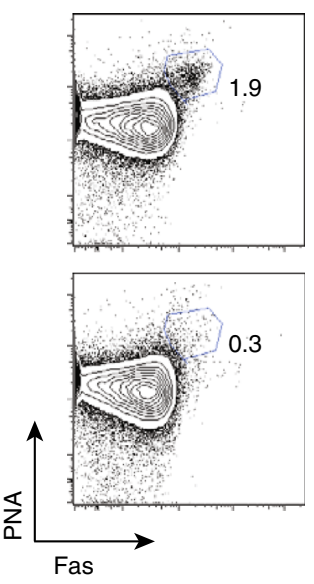
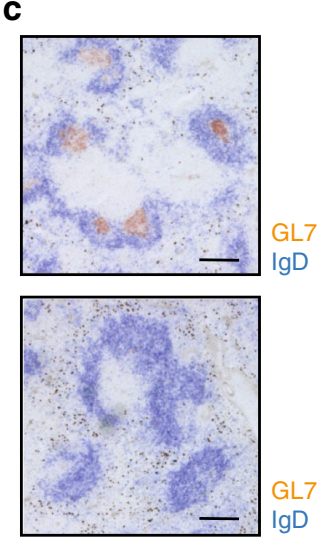

d
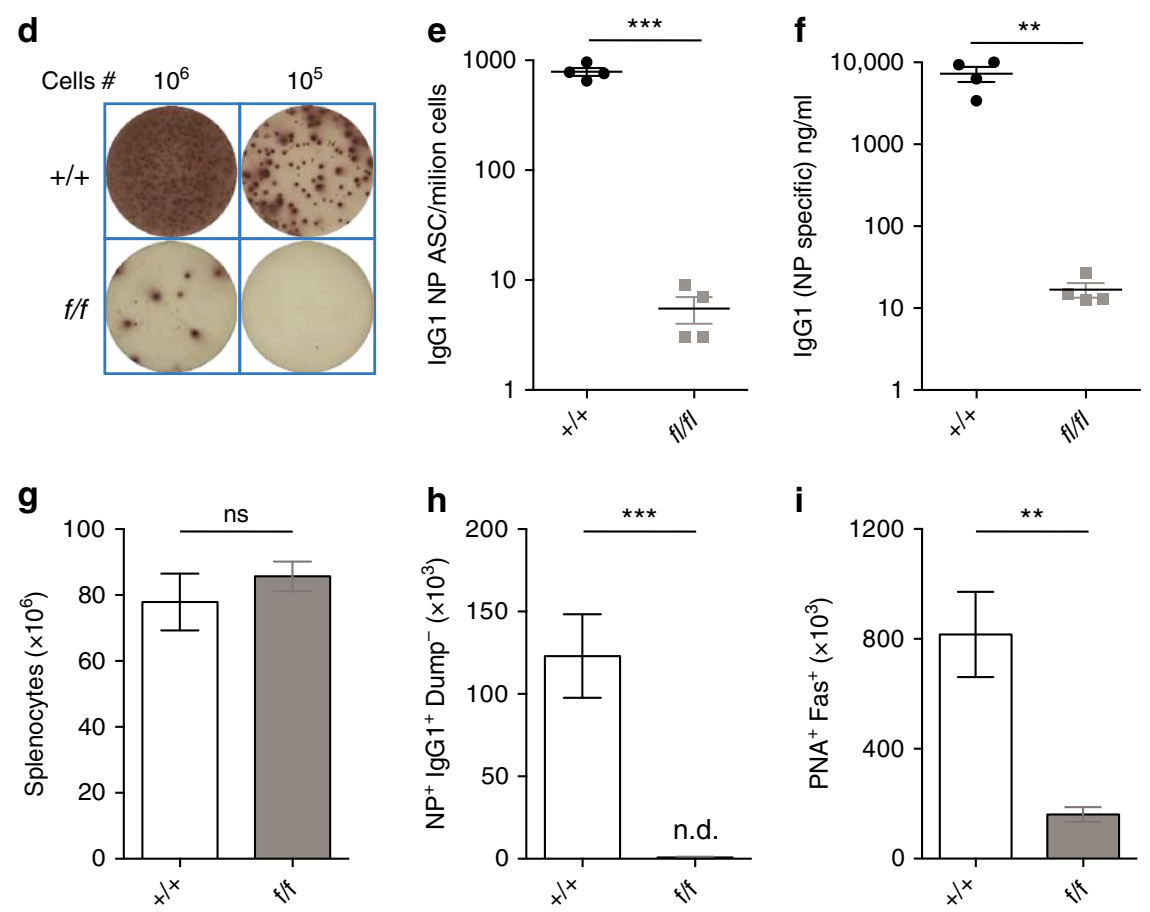

Fig. 4 PRMT1 is required for GC formation in response to immunization. a Control mice were immunized with NP-KLH in alum and the indicated B-cell subsets were sorted from spleen 7 days post immunization, lysed and proteins separated by SDS-PAGE. Western blot analysis shows PRMT1 (top panel), asymmetrically methylated arginine-containing proteins (middle panel) and actin (loading control, bottom panel) in non-GC B cells (CD19 ${ }^{+}$Fas ${ }^{-}$PNA ${ }^{-}$), GC $\mathrm{B}$ cells $\left(\mathrm{CD} 19^{+} \mathrm{Fas}^{+} \mathrm{PNA}^{+}\right)$and $\mathrm{ASC}\left(\mathrm{CD} 138^{+} \mathrm{B} 220^{\text {low }}\right)$. b-i Control $(+/+)$ and Prmt $f^{f / f} \mathrm{CD} 23 \mathrm{Cre}(f / f)$ mice were immunized with NP-KLH in alum and analyzed at day 7. b NP-specific lgG1 ${ }^{+}$B cells (left) and total GC B cells (right) are shown in representative flow cytometry plots. Numbers indicate frequency of indicated events within the B220 $0^{+}$ump $^{-}$. Dump antibodies detected IgM; IgD; Gr1. c Immunohistochemical staining for GC in spleen sections at day 7 post NP-KLH immunization using GL7 (orange) and IgD (blue) with scale bars indicating $100 \mu \mathrm{m}$. Representative wells $\mathbf{d}$ and frequency per million splenocytes e of NP-specific $\operatorname{lgG} 1^{+}$ASC as measured by ELISpot at day 7 post immunization. $\mathbf{f}$ Serum titres of NP-specific lgG1 antibody as determined by ELISA at day 7. Total splenocyte number $\mathbf{g}$, number of NP-reactive $\operatorname{lgG} 1^{+}$B cells $\mathbf{h}$ and $\mathrm{GC} \mathrm{B}$ cells $\left(\mathrm{PNA}^{+}\right.$Fas ${ }^{+}$) $\mathbf{i}$, calculated at day 7 post immunization of control $(+/+)$ and $\operatorname{Prmt} 1^{f / f} \mathrm{CD} 23 \mathrm{Cre}(f / f)$ mice as indicated. ${ }^{\star \star} P \leq 0.01,{ }^{\star \star \star} P \leq 0.001$; ns $=$ not significant (unpaired $t$-test). Data are representative of three independent experiments with four mice per group. Mean and s.e.m. in e-i. Uncropped images of blots are presented in Supplementary Fig. 5. Flow cytometry gating strategies for this figure are shown in Supplementary Fig. 8

revealed that the basal oxygen-consumption rate (OCR) in unstimulated B cells was not influenced by Prmt1 deficiency (Supplementary Fig. 2a) but conversely, PRMT1 was required for basal and maximal respiratory capacity as well as glycolytic capacity in activated B cells (Supplementary Fig. 2a-c). Thus, PRMT1 activity was required for normal B-cell responses to stimuli that mimic aspects of T-cell dependent (TD) or T-cell independent (TI) responses and this included the metabolic reprogramming that follows activation.
PRMT1 is required in B cells for humoral immunity. The increased amounts of PRMT1 and asymmetrically arginine methylated proteins following in vitro activation of B cells suggested that similar changes might occur in in vivo activated $\mathrm{B}$ cells. We purified therefore naive B cells, germinal centre (GC) B cells and ASC from mice 7 days after immunization with a TD antigen, prepared lysates and probed each sample for both PRMT1 and proteins containing asymmetrically dimethylated arginines (Fig. 4a). The amount of PRMT1 was low in non-GC 

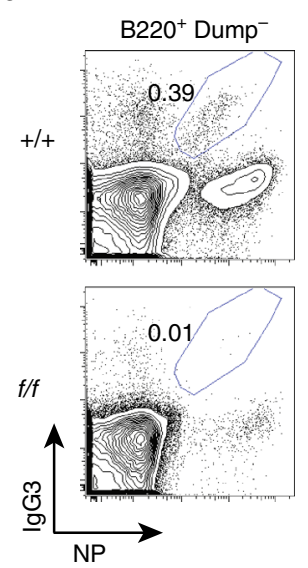

d

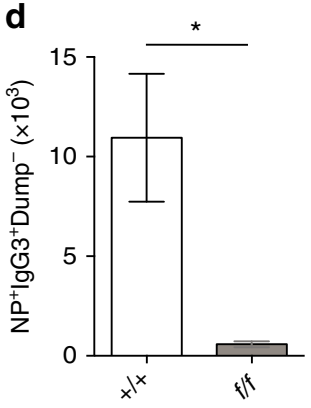

g

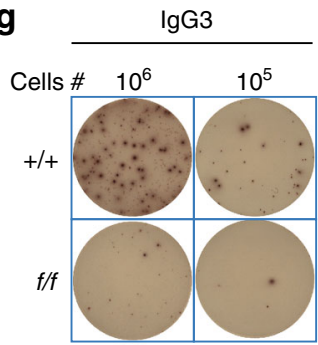

Unimmunized b
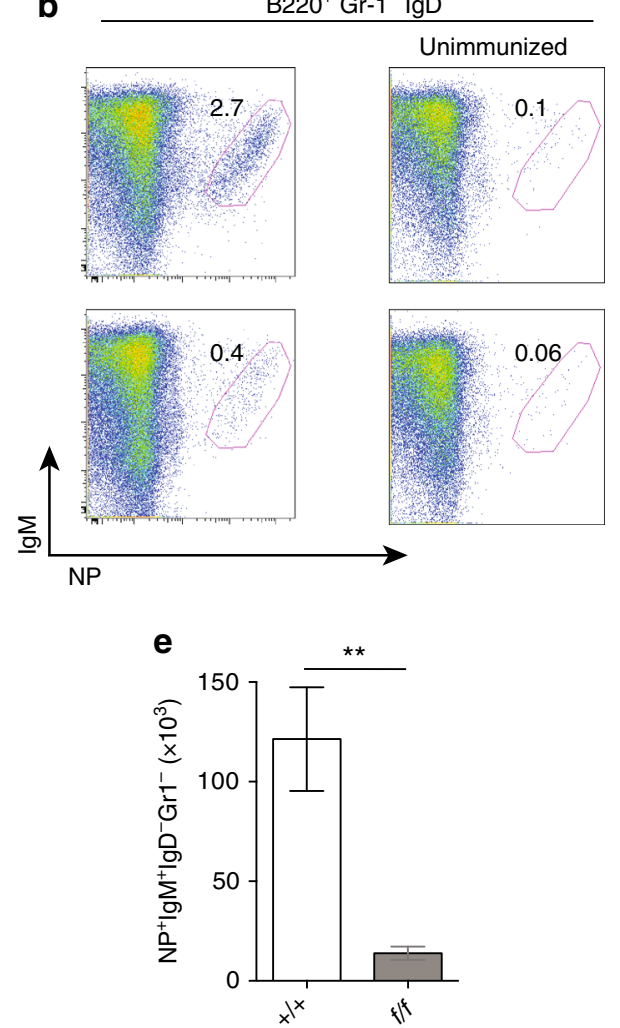

h
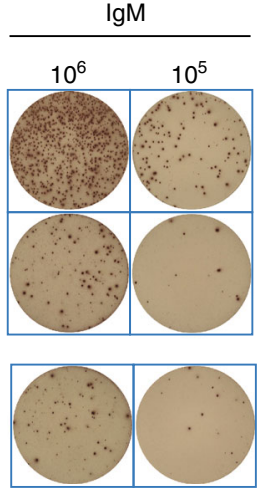

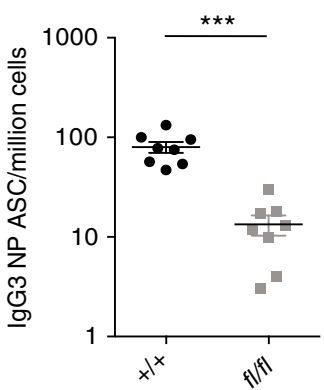

$3220^{+} \mathrm{Gr}-1^{-} \lg \mathrm{D}^{-}$

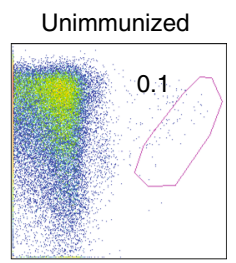

C
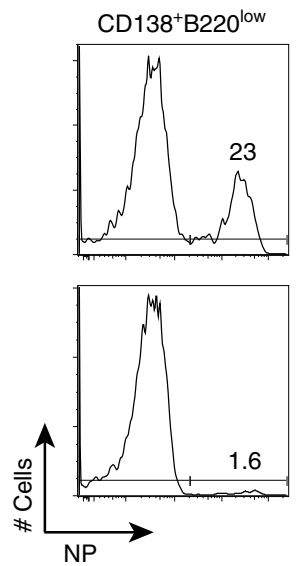

f

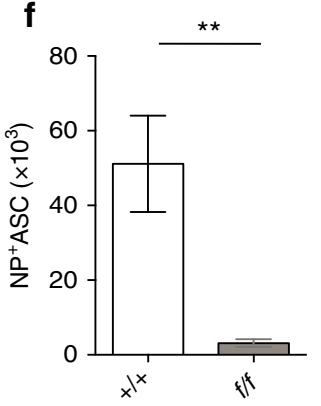

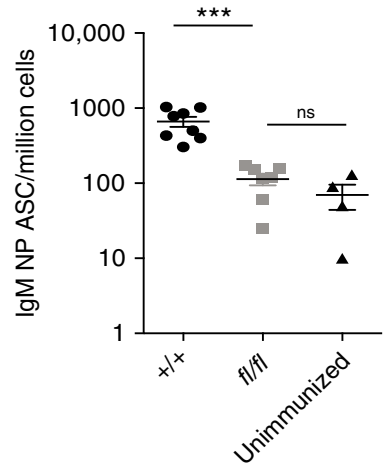

Fig. 5 PRMT1 is critical for a TI immune response. Control $(+/+)$ and Prmt $7^{f / f} \mathrm{CD} 23 \mathrm{Cre}(f / f)$ mice were injected i.p. with NP-Ficoll and analysed after 5 days. Splenic NP-specific $\mathbf{a} \operatorname{lgG}{ }^{+}$and $\mathbf{b} \operatorname{lgM}^{+} B$ cells are shown in representative flow cytometry plots along with an unimmunized mouse for lgM in (upper) control $(+/+)$ and (lower) Prmt $7^{f / f} C D 23 C r e(f / f)$ mice. c Histograms display the proportion of spleen ASC (CD138 ${ }^{+}$B220 low) that were NP-specific at day 5 post immunization in (upper) control $(+/+)$ or (lower) Prmt $t^{f / f} C D 23 C r e(f / f)$ mice. a-c Numbers represent the frequency of events within the indicated regions. d-f Numbers of splenic NP-specific $\operatorname{lgG} 3^{+}$B cells d, NP-specific $\lg M^{+} B$ cells $\mathbf{e}$ and NP-specific ASC $\mathbf{f}$ are shown. Representative wells $\mathbf{g}$ and frequency $\mathbf{h}$ of NP-specific $\operatorname{lgG} 3^{+}$and $\lg \mathrm{M}^{+} \mathrm{ASC}$ as measured by ELIspot in the spleen and presented as ASC per million spleen cells. Naive lgM ELISpot sample $\mathbf{g}$ is from control $(+/+)$ mice. ${ }^{\star} P \leq 0.05 ;{ }^{\star \star} P \leq 0.01 ;{ }^{\star \star \star} P \leq 0.001$; ns $=$ not significant (unpaired $t$-test). Data are representative of two independent experiments with four mice per group. Mean and s.e.m. in $\mathbf{d}-\mathbf{f}$ and $\mathbf{h}$. Flow cytometry gating strategies for this figure are shown in Supplementary Fig. 9

splenic B cells, but increased in both GC B cells and, to a lesser extent, in ASC. Probing lysates for asymmetrically argininemethylated proteins revealed few bands in naive $B$ cells, but these increased in number and amount in both the GC B cell and ASC samples (Fig. $4 \mathrm{a})$. We purified also naive $\left(\mathrm{CD} 20^{+} \mathrm{CD} 27^{-} \mathrm{CD} 38^{\mathrm{lo}}\right)$, $\mathrm{GC}\left(\mathrm{CD} 20^{\mathrm{hi}} \mathrm{CD} 27^{+} \mathrm{CD} 38^{\mathrm{hi}}\right)$ and memory $\left(\mathrm{CD} 20^{+} \mathrm{CD} 27^{+} \mathrm{CD} 38^{\mathrm{lo}}\right)$ $\mathrm{B}$ cells from human tonsils and found PRMT1 to be readily detected in all samples, although the amount was slightly increased in GC B cells (Supplementary Fig. 1b). Examining these samples for proteins containing asymmetric dimethlyated arginines revealed a similar pattern in all cell types, but with some bands of increased intensity in the memory and GC B-cell fractions (Supplementary Fig. 1c). Thus, human B cells ex vivo also showed activation-dependent increases in PRMT1 amounts and protein arginine methylation.

To assess possible functions of PRMT1 in B-cell responses in vivo, Prmt $1^{f / f}$ CD23Cre and control mice were immunized intraperitoneally with the TD antigen (4-hydroxy-3-nitrophenyl) acetyl coupled to keyhole limpet hemocyanin (NP-KLH) delivered with an alum adjuvant. In the ensuing immune 
response, we monitored the frequency of isotype-switched, antigen-specific B cells and total GC B cells (Fig. 4b). Remarkably, $\mathrm{NP}^{+} \mathrm{IgG1} 1^{+} \mathrm{B}$ cells, $\mathrm{PNA}^{+} \mathrm{FAS}^{+} \mathrm{GC}$ B cells and physical GC structures were not detected in the spleens of immunized Prmt $1^{f /}$ ${ }^{f} \mathrm{CD23Cre}$ mice, in contrast to their abundance in control mice (Fig. 4b, c). Whether Prmt1-deficient B cells generated NPspecific $\mathrm{IgG1}^{+}$ASC in spleen or NP-specific serum antibody in vivo was determined by ELISpot assays and ELISA, which revealed a more than 100-fold reduction in both ASC frequency and antibody titres in Prmt $1^{f / f}$ CD23Cre mice (Fig. 4d-f). Importantly, these differences were reflected as absolute numbers (Fig. $4 \mathrm{~g}-\mathrm{i}$ ) with similar differences recorded 5 and 14 days after immunization. To determine whether a defective immune response was restricted to hapten antigens, we infected Prmt f $^{f / f}$ CD23Cre mice with influenza virus and found similar defects in GC and ASC production (Supplementary Fig. 3). In this case, both Prmt $1^{\text {flf }} \mathrm{CD} 23 \mathrm{Cre}$ and control mice increased the number of $\mathrm{CD} 8^{+} \mathrm{D}^{\mathrm{b}} \mathrm{NP} 366$-binding cells, confirming successful infection and an absence of any global immune suppression in Prmt $1^{f l}$ ${ }^{f}$ CD23Cre mice (Supplementary Fig. 3d, e).

Prmt $1^{\text {flf }} \mathrm{CD} 23 \mathrm{Cre}$ mice were also challenged with NP-Ficoll, a TI antigen, and again failed to generate a normal response (Fig. 5). While the frequency of $\mathrm{NP}^{+} \mathrm{IgM}^{+} \mathrm{B}$ cells increased in the spleens of Prmt $1^{f / f}$ CD23Cre mice following this immunization (Fig. 5b), indicating a degree of clonal expansion, this was substantially less than occurred in controls, as was the amount of NP-specific IgG3 antibody in serum (Fig. 5d-h). Thus, responses to both TD and TI antigens were defective in mice with Prmt1deficient $\mathrm{B}$ cells.

Immune defects are strictly B-cell intrinsic. The immune defects identified in mice with Prmt1-deficient B cells could in principle arise from an inability of such $\mathrm{B}$ cells to induce appropriate $\mathrm{CD} 4^{+}$ T-cell help, potentially compounding an otherwise modest B-cell defect. We examined this possibility by creating $\mathrm{BM}$ radiation chimeras with $50 \%$ of hematopoietic cells derived from Ly5.2 Prmt $1^{f / f}$ CD23Cre BM and 50\% from Ly5.1 congenic BM that was Prmt1 wild type. Control chimeras were made with equal amounts of Ly5.2 CD23Cre and Ly5.1 BM, all cells being Prmt1 sufficient. Nine weeks after reconstitution, both groups of mice were immunized with NPKLH in alum and analyzed 7 days later for the presence of antigenspecific B cells of either allotype in the spleen (Supplementary Fig 4). Prmt1-deficient B cells, although equally represented in the naive $\mathrm{B}$-cell population, failed to generate detectable $\mathrm{NP}^{+} \mathrm{IgG} 1^{+} \mathrm{B}$ cells, despite the presence of control $\mathrm{NP}^{+} \mathrm{IgG1} 1^{+} \mathrm{B}$ cells and T-cell help (Supplementary Fig. 4a, b). The same Prmt1-deficient B-cell deficit was apparent in the NP-specific ASC compartment, identified as $\mathrm{NP}^{+} \mathrm{CD} 138^{+} \mathrm{B} 220^{\mathrm{lo}}$ and then partitioned by expression of Ly5.1 (Supplementary Fig. 4c, d). In control chimeras, both allotypes were represented equally in the NP-reactive B-cell and ASC populations (Supplementary Fig. 4). The immune response defect was still apparent when we examined all GC B cells, irrespective of specificity. Thus, Prmt1-deficient B cells were unable to either initiate or enter into a GC reaction.

PRMT1 is required in B cells for a memory response. The previous experiments revealed a requirement for PRMT1 in B cells for normal humoral immune responses. These data, however, did not test whether PRMT1 was required in memory B cells to mount a recall response. To assess this requirement, we first created mice in which Prmt1 deficiency was both inducible and restricted to the B-cell lineage. This was done by reconstituting lethally irradiated recipients with a BM mixture comprising $80 \%$ from mice homozygous for the $\mu \mathrm{MT}$ mutation, and thus unable to generate B cells ${ }^{25}$, and $20 \%$ from mice that were Prmt $1^{f / f}$ and
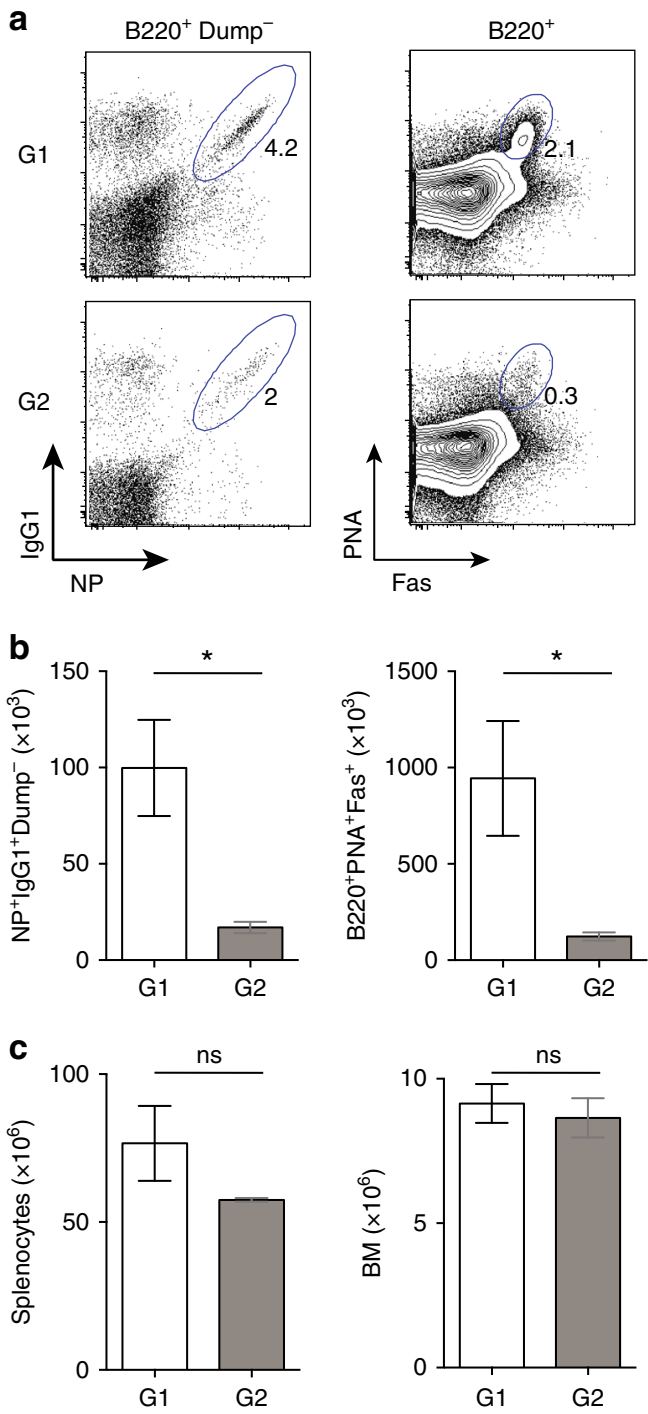

Fig. 6 PRMT1 is required to mount a recall immune response. a-c Irradiation chimeras were generated with $80 \%$ of $\mu \mathrm{MT}$ and either $20 \%$ of Prmt1 ${ }^{+/+}$Rosa26CreERT2 (G1;+/+) or 20\% Prmt1//f Rosa26CreERT2 (G2; f/f) BM cells. Nine weeks post BM reconstitution; mice were immunized with NP-KLH in alum. Nine weeks after immunization mice were treated for 3 days with single doses of Tamoxifen to induce Prmt1 deletion and then boosted with NP-KLH in PBS, injected i.p. a Representative flow cytometry plots of splenocytes 5 days after NP-KLH boost are shown. Frequencies of $\mathrm{NP}^{+} \operatorname{lgG} 1^{+}$(left) and total GC (B220 ${ }^{+} \mathrm{Fas}^{+} \mathrm{PNA}^{+}$) (right) among $\mathrm{B}^{2} 2 \mathrm{O}^{+} \mathrm{lgM}$ ${ }^{-} \mid \mathrm{gD}{ }^{-} \mathrm{Gr}^{-}$cells and $\mathrm{B} 22 \mathrm{O}^{+}$cells, respectively, are indicated. Numbers represent percentages of the displayed events within indicated gates. $\mathbf{b}, \mathbf{c}$ Average numbers of $\mathrm{NP}^{+} \operatorname{lgG} 1^{+}$B-cells, GC B cells, total splenocytes per spleen and per femur are shown in the graphs. ${ }^{\star} P \leq 0.05$; ns $=$ not significant (unpaired $t$-test). Mean and s.e.m. (b, c). The experiment comprised five mice per group. Flow cytometry gating strategies for this figure are shown in Supplementary Fig. 10

carried the Rosa26CreERT2 allele encoding a constitutively expressed, Tamoxifen inducible form of $\mathrm{Cr}^{26}$. In control chimeric mice, the $20 \%$ BM donor was Prmt ${ }^{+/+}$Rosa26CreERT2. After reconstitution, these two groups of mice were immunized with NP-KLH in alum and 9 weeks later, dosed on 3 successive days with Tamoxifen to induce activation of Cre and deletion of the Prmt $\mathrm{f}^{\mathrm{f} / \mathrm{f}}$ alleles. The mice were then boosted with soluble NP$\mathrm{KLH}$ and examined 5 days later for the presence of both NP-specific B cells and GC B cells (Fig. 6). Boosted mice in which 
a

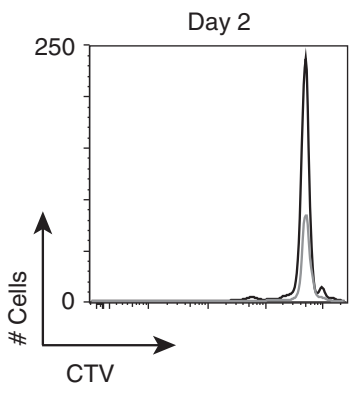

b

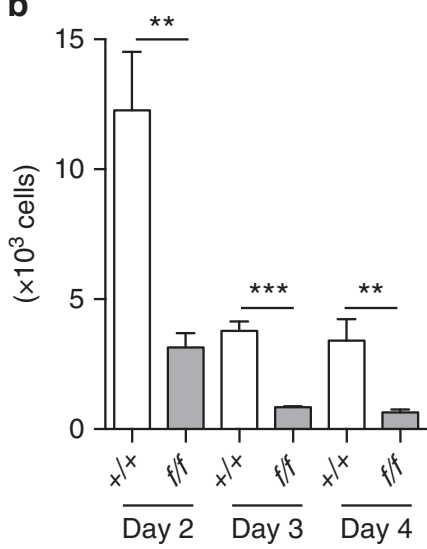

Day 3
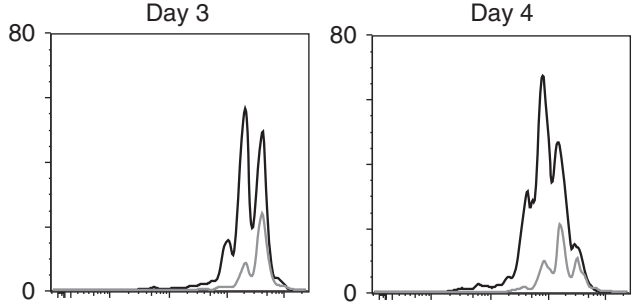

C

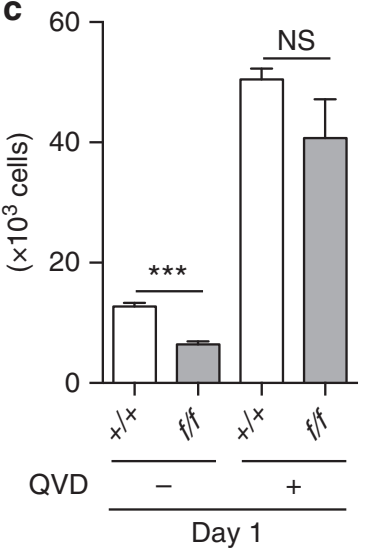

d

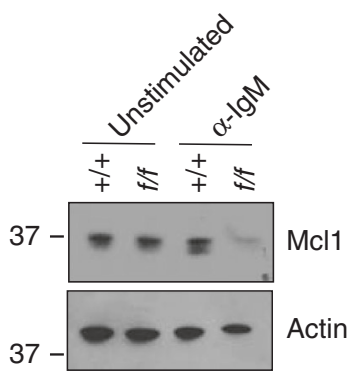

e

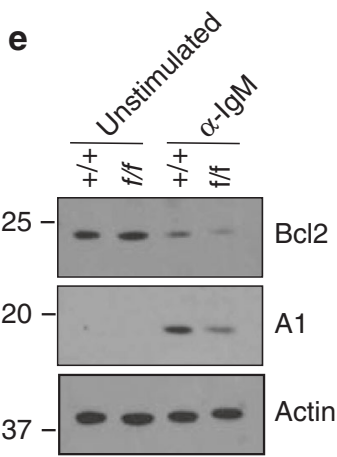

$\mathbf{f}$

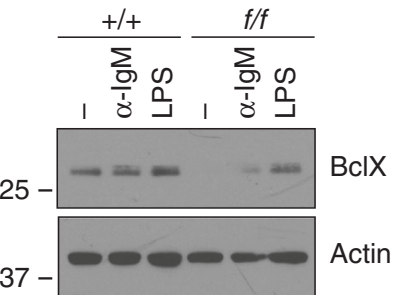

Fig. 7 Prmt1-deficient B cells respond abnormally to in vitro stimulation. a, b Splenic B cells, purified from control $(+/+)$ and Prmt $1^{f / f} C D 23 C r e(f / f)$ mice, were labelled with CTV and cultured in the presence of $F\left(a b^{\prime}\right)_{2}$ anti-lgM antibody for the indicated times. a Overlay histograms show division profiles of live cells at days 2, 3 and 4 of activation for control (black line) and Prmt1-deficient (grey line) B cells. b Quantification of live cells at time points indicated after stimulation for control $(+/+)$ and Prmt7-deficient $(f / f)$ samples. c Control $(+/+)$ and Prmt1-deficient B cells $(f / f)$ were activated with F(ab') $)_{2}$ anti-lgM antibody for $24 \mathrm{~h}$ in the presence or absence of the broad caspase inhibitor, QVD. Viable cell numbers are indicated. $\mathbf{b}, \mathbf{c}^{\star \star} P \leq 0.01 ;{ }^{\star \star \star} P \leq 0.001 ; \mathrm{ns}=\mathrm{not}$ significant (unpaired $t$-test). Data are representative of three experiments with three replicates per experiment. Mean and s.e.m. $\mathbf{d}$-f Defective regulation of MCL1, BCL2, A1 and BCLX in activated Prmt1-deficient B cells. Immunoblot analysis of spleen B cells from control $(+/+)$ and Prmt $T^{f / f} \mathrm{CD} 23 \mathrm{Cre}(f / f)$ mice. $\mathbf{d}$, e $B$ cells were unstimulated or activated for $24 \mathrm{~h}$ with $\mathrm{F}\left(a b^{\prime}\right)_{2}$ anti-lgM, then lysed and separated by SDS-PAGE. $\mathbf{d}$ MCL1 and e BCL2 and A1 protein amounts were detected with the respective antibodies. $f$ Control $(+/+)$ and $P r m t t^{f / f} C D 23 C r e(f / f)$ spleen $B$ cells were unstimulated $(-)$, activated with $F(\text { ab' })_{2}$ anti$\operatorname{lgM}(\alpha-\operatorname{lgM})$ or LPS for $24 \mathrm{~h}$, then lysed and separated by SDS-PAGE. BCLX protein was detected by specific antibody as indicated. $\mathbf{d}-\mathbf{f}$ Actin was used as a loading control and comparable results were obtained in three independent experiments. Uncropped images of blots are presented in Supplementary Fig. 5 . Flow cytometry gating strategies for this figure are shown in Supplementary Fig. 11

Prmt1 had been deleted from memory B cells showed a significant deficit in $\mathrm{NP}^{+} \mathrm{IgGl}^{+}$and GC B cells compared to controls in which Prmt1 was retained (Fig. 6a, b). Importantly, this treatment did not significantly reduce the overall number of B cells in spleen or BM (Fig. 6c). Thus, as in a primary immune response, PRMT1 activity was required for a normal memory B-cell response.

PRMT1 regulates survival following BCR ligation. B-cell responses to $\mathrm{TD}$ antigens depend on stimulation through CD40L and the BCR. While the reduced proliferation and differentiation of Prmt1-deficient B cells in response to stimulation with CD40L and cytokines could contribute to defective immunity, it was possible that other pathways were affected. To determine whether Prmt1 deficiency altered proliferation following BCR ligation, B cells purified from spleens of Prmt1 $1^{f / f}$ CD23Cre and control mice were labelled with CTV and cultured for 4 days in the presence of $\mathrm{F}\left(\mathrm{ab}^{\prime}\right)_{2}$ anti-IgM to crosslink the BCR (Fig. 7a, b). On days 2, 3 and 4 , the number of cells present in the cultures and the extent of cell division were assessed, revealing a reduced number of divisions, a reduced number of cells in each division and significantly reduced overall viability at 
all times for Prmt1-deficient B cells compared to controls (Fig. 7a, b). The nature of the cell death induced by BCR ligation was examined by repeating the cultures in the presence of the pancaspase inhibitor, QVD, which reduced cell death at $24 \mathrm{~h}$ such that viability in the Prmt $f^{f / f}$ CD23Cre and control cultures was equal (Fig. 7c).

That QVD blocked the increased apoptosis in Prmt1-deficient B cells following BCR stimulation suggested a connection between PRMT1, BCR ligation and the proteins that protect against activation induced cell death ${ }^{27}$. We examined therefore the amounts of BCL2 family members MCL1, BCL2, A1 and BCLX in Prmt1 flf CD23Cre and control B cells before and after stimulation with anti-IgM (Fig. 7d-f). MCL1, which was equally abundant in unstimulated Prmt ${ }^{f / f} \mathrm{CD} 23 \mathrm{Cre}$ and control B cells, was reduced in Prmt1-deficient B cells following BCR ligation. BCL2 decreased in both control and Prmt1 flf CD23Cre B cells following BCR ligation, but to a greater extent in Prmt1-deficient B cells. A1 was induced in both groups, but less so in Prmt $1^{f / f}$ CD23Cre B cells (Fig. 7e). BCLX was detectable in equal amounts prior to and after both stimulations in control B cells, but was barely detectable in unstimulated Prmt1-deficient B cells and increased marginally following BCR ligation (Fig. 7f). Thus, PRMT1 was required for appropriate regulation of expression of pro-survival members of the BCL2 family in B cells before and after BCR stimulation such that in its absence, apoptosis was significantly increased.

\section{Discussion}

PRMT1, considered the predominant type I arginine methyltransferase activity in mammalian cells, regulates a multitude of molecular and cellular functions ${ }^{2}$. This includes gene transcription, responding to DNA damage, mRNA translation, cell division, apoptosis and signal transduction ${ }^{14}, 18,19,28,29$. Despite such individual examples, potential roles for PRMT1 in B-cell immune responses have not previously been reported. In the present study we have examined the role of PRMT1 in mature B cells. We have shown that the increased activity of PRMT1 upon B-cell activation serves to co-ordinate a number of crucial processes that are required for a successful immune response and that are dysregulated in its absence. These dysregulated processes include cell cycle progression, metabolism and survival, the last two being novel findings of this work. Indeed, the altered expression of BCL2 family pro-survival proteins in the absence of PRMT1 could be a major contributor to the immunodeficiency we have observed in these mice, as MCL1, one of the altered proteins, is essential for GC B-cell and plasma cell survival ${ }^{26}, 30$.

Asymmetrically dimethylated arginine proteins are present in naive $B$ cells before increasing in amount significantly following B-cell activation. Given that we found protein methylation activity to be essentially undetectable in naive B cells over a 3-h interval in vitro, this result implies that arginine methylation is a particularly stable post-translational change in these cells. Interestingly, we observed several novel asymmetrically methylated protein bands in both control and Prmt1-deficient B-cell samples following stimulation, indicating unique and redundant substrates of PRMT1 that presumably participate in the processes that are dysregulated in the enzyme's absence. Identifying these substrates and the activities that are dependent on PRMT1 will be the basis of significant future work, determining how methylation modulates their roles in proliferation, differentiation and survival following B-cell activation by a variety of stimuli.

Activation of Prmt1-deficient B cells is associated also with significant apoptosis. This cell death could reflect the defect in mitochondrial respiratory capacity, meaning that PRMT1 is required for either the metabolic changes that sustain B-cell growth and viability following activation, or to integrate those changes into a viability signal. The marked dysregulation in expression of pro-survival members of the BCL2 family of proteins observed in response to BCR stimulation of Prmt1-deficient B cells could also contribute to increased apoptosis. Specifically, the inability of Prmt1-deficient B cells to sustain MCL1 and BCL2 proteins following BCR ligation, or to upregulate and/or maintain A1 protein and BCLX could all contribute to increased cell death after BCR ligation. Indeed, the ability of the broad caspase inhibitor, QVD, to block apoptosis of Prmt1-deficient B cells is consistent with such a role. These results reveal a previously undescribed role for PRMT1 in cell death. Collectively, impairments in proliferation, differentiation, metabolism and survival could combine to create the near-complete block in B-cell immune responses observed in vivo.

The consequences on in vivo B-cell behaviour of Prmt1 deletion are not restricted by the nature of the antigen. We observed a deficit of plasma cells and GC B cells in mice containing Prmt1deficient $\mathrm{B}$ cells following either immunization with a protein antigen in adjuvant or infection with influenza virus. In response to immunization, antigen-specific, isotype-switched antibody is detected in the serum of Prmt1-deficient mice along with rare IgG1 ASC in spleen, suggesting at a minimum the initiation of an immune response. That we measured equal expansion of influenza specific $\mathrm{CD}^{+} \mathrm{T}$ cells in control and Prmt ${ }^{f / f} \mathrm{CD} 23 \mathrm{Cre}$ mice following infection rules out technical issues or systemic immune suppression in the Prmt1-deficient group. Similarly, observing a degree of clonal expansion in response to NP-Ficoll, indicates that antigen specific Prmt1-deficient B cells were exposed to and at least transiently activated by antigen. Reflecting these in vivo results, in vitro proliferation of Prmt1-deficient B-cells in response to a range of mitogens, although significantly less than in controls, does occur to some extent. We also investigated the requirement for PRMT1 in a memory B-cell response to a TD antigen and found it again to be indispensable. Our finding that PRMT1 protein expression and activity in human B cells mirrored that in mice B cells-being higher in GC and plasma cells compared to naive $\mathrm{B}$ cells and being induced by in vitro activation - suggests the roles of PRMT1 in B cells will be conserved between these species and that inhibiting PRMT1 activity may be beneficial in situations of pathogenic B-cell hyperactivity.

Arginine methylation within the cytoplasmic tail of Ig- $\alpha$ alters the consequences of ligation of the pre-BCR, increasing the activity of $\mathrm{PI} 3 \mathrm{~K}$ and thus promoting differentiation over proliferation ${ }^{14}$. We showed here in mature $\mathrm{B}$ cells that BCR ligation in the absence of PRMT1 also leads to elevated and prolonged PI3K activation, as indicated by PKB phosphorylation. Similarly, and perhaps counterintuitively given the overall hyporesponsiveness at the cell level, total protein tyrosine phosphorylation was increased and prolonged in PRMT1-deficient B cells, as was phosphorylation of FOXO1 and ERK1/2. These results suggest that in the period shortly after BCR stimulation, PRMT1 acts as a negative regulator of signalling in a role that is apparent in both pre-B and follicular B cells.

PRMT1 regulates the activity and/or persistence of FOXO1 by controlling the access of $\mathrm{PKB}^{17}, 18$. Interestingly, FOXO1 is active in GC B cells where its predominant role is to establish the dark zone $(\mathrm{DZ})^{28,31}$. FOXO1 is required also for class switch recombination and affinity maturation in vivo ${ }^{28}, 31$. Equally, PI3K activity is an important regulator of both GC formation and class switch recombination, promoting cell survival and proliferation on one hand and repressing AID activity on another ${ }^{32}$. The compromised appearance of GC and class switched, antigenspecific B-cells in mice carrying Prmt1-deficient B cells could be explained in part by reduced FOXO1 arginine methylation leading to increased phosphorylation by $\mathrm{PKB}$ and thus 
inactivation. These consequences of not methylating FOXO1 could be amplified by the extended PI3K activity we observed in Prmt1-deficient B cells following BCR ligation. Thus, the combined effects of dysregulated FOXO1 and PI3K activity could perturb B-cell proliferation, class switch recombination, plasma cell differentiation and ultimately the GC reaction. Determining the precise mechanisms by which PRMT1 activity regulates different components of B-cell activation will be a challenging but essential part of understanding how this enzyme coordinates multiple aspects of B-cell biology.

PRMT1 has many substrates ${ }^{2}$, which may explain why its absence has such profound, heterogeneous and often cell typeand stage-specific effects. For example, PRMT1 could be involved in regulating proliferation through its action on MRE11, which is thought to contribute to the chromosomal instability and cell cycle checkpoint abnormalities seen in PRMT1 deficient embryonic fibroblasts ${ }^{19,33}$. More recently, PRMT1 was shown to methylate cyclin-dependent kinase 4 (CDK4) in FOXO1expressing pre- $\mathrm{B}$ cells, preventing or disrupting complexes between CDK4 and cyclin-D3, and thereby blocking cell cycle progression and promoting differentiation ${ }^{34}$. It is possible that either or both these activities contribute to the deficit of B-cell expansion observed here in vitro and in vivo and further work will identify the relevance of these mechanisms in mature B cells.

It is possible also that the consequences of Prmt1 deletion in B cells are mediated not by the loss of PRMT1 activity per se, but rather through a concomitant alteration in the activity of another PRMT, which is what actually affects the GC reaction and plasma cell differentiation ${ }^{35}$. The activity of the transcription factor E2F1 , for example, varies depending on the relative amounts of PRMT1 and PRMT5, which compete for access to the same methylation site, promoting apoptosis and proliferation, respectively $^{36}$. In addition to the role of PRMT1 in GC formation reported here, PRMT7 has been shown to repress transcription of $B c l-6$ via H4R3 methylation in its promoter ${ }^{37}$. Deletion of Prmt7 in B cells increases Bcl6 expression, promoting GC development and repressing Irf4 and Prdm1, genes that are required for plasma cells differentiation ${ }^{37}$. Conceivably, any interplay between PRMT1 and PRMT7 in which one affected the activity of the other, could contribute to the in vivo B-cell phenotype observed here. The intersection of the activities of the different PRMT, which may be substrate specific, suggests an assessment of all remaining arginine methylation activity may be required to fully understand the mechanisms underlying the phenotypes observed in the absence of any individual PRMT.

A previous report has described normal TD responses and abnormal TI responses in B-cell Prmt1-deficient mice ${ }^{38}$. B cells from these mice were also found to be normal or even augmented in their proliferation in response to mitogen stimulation in vitro. However, these earlier studies differed from those reported here in two respects. First, Prmt1 was deleted in the earliest stages of B-cell development using a CD19-Cre, potentially enabling compensation of its absence during development. Second, Prmt1 deletion was incomplete with PRMT1 protein detected in peripheral B cells, which means some of the reported results may be dosage related ${ }^{38}$.

In conclusion, our results identify PRMT1 as a central regulator of humoral immunity, establishing a previously unidentified role of this enzyme in the activation, proliferation and differentiation of $B$ cells. Our findings have demonstrated the dynamic induction of arginine methylation in activated $\mathrm{B}$ cells and have revealed striking similarities in PRMT1 expression and activity between mouse and human B cells, suggesting conserved roles in supporting proper immune responses in both species. We have also established that, in activated B cells, PRMT1 is required to sustain MCL1 and BCL2 protein expression, revealing a previously unknown role of PRMT1 in apoptosis. Overall, our studies indicate that PRMT1 activity may be essential to integrate multiple pathways into a coherent outcome that is manifest as both $B$ cell activation and an immune response.

\section{Methods}

Mice and immunizations. $C d 23 \mathrm{Cre}$ mice ${ }^{20}$ were provided by Meinrad Busslinger and the creation of Prmt $1^{f / f l}$ mice has been described ${ }^{19}$. All mice were maintained at the Walter and Eliza Hall Institute of Medical Research (WEHI) on a C57BL/6 background. Animal procedures were approved by the WEHI Animal Ethics Committee and mice used in the study were male or female, and 8 weeks of age on commencement. No animals were specifically excluded from the study and the investigators were not blinded to the groups during the experiments or analyses. For primary immune responses, mice were injected intraperitoneally (i.p.) with $100 \mu \mathrm{g}$ of 4-hydroxy-3-nitrophenyl)acetyl (NP) conjugated to keyhole limpet hemocyanin (KLH) at a molar ratio of (13-20):1, precipitated on $10 \%$ alum. For secondary responses, mice were boosted i.p. with $50 \mu \mathrm{g}$ of NP-KLH in PBS. Sample sizes were calculated to detect with $80 \%$ power a difference of at least $30 \%$ in the means with a variance of $20 \%$, with equal numbers in all groups. For influenza infections mice were inoculated with $10^{4}$ p.f.u. of HKx31 (H3N2) influenza virus ${ }^{39}$.

Flow cytometry, antibodies and cell purification. Single cells were resuspended in PBS 2\% FCS and stained for flow cytometric analysis, with dilution of antibodies ranging between 1:100 and 1:800. The following reagents were used: Ly5.2 (104), CD138 (281), IgG1 (X56), Fas/CD95 (Jo2), Ly5.1 (A20.1) and CD19 (1D3) from Becton Dickinson Biosciences (BD); PNA from Vector Laboratories; IgG3 from Southern Biotech; CD93 (AA4.1) from eBioscience; GL7 (GL7), Gr1 (8C5), IgM (331.12), IgD (11/26), CD21 (76G), CD23 (B3B4), CD8 (53-6.7) and B220 (RA36B2) were conjugated in-house. Human antibodies: CD20 (2H7), CD27 (M-T271) and CD38 (HIT2) from BD. Virus-specific $\mathrm{CD}^{+} \mathrm{T}$ cells were detected with tetrameric $\mathrm{H}-2 \mathrm{~b}$ major histocompatibility complex with the influenza virus nucleoprotein peptide (NP; H-2Db-restricted NP 336-374) ${ }^{39}$. Fc $\gamma$ RII/III (24G2; supernatant) was used to block non-specific antibody binding. For western blot and in vitro activation, cells were analyzed live (with the addition of propidium iodide) on the FACS CantoII (Becton Dickinson-BD) and data analyzed using Flowjo software (Treestar). Splenic B cells from control $(+/+)$ or $(f / f)$ mice were obtained using the B-cell isolation kit and LS magnetic columns, following the manufacturer's protocol (Miltenyi Biotech GmbH). Human B cells were isolated from PBMC or tonsils using CD19 microbeads and LS magnetic columns (Miltenyi Biotech) and further processed as indicated. B-cell purity $(>98 \%)$ was determined using CD19 and B220 antibodies. Sort-purification: cells were stained with antibodies as indicated and purified by FACS Aria or Influx (BD), with purity $>98 \%$. Mouse naive (non-GC) $\left(\mathrm{CD} 19^{+} \mathrm{Fas}^{-} \mathrm{PNA}^{-}\right), \mathrm{GC}\left(\mathrm{CD} 19^{+} \mathrm{Fas}^{+} \mathrm{PNA}^{+}\right)$and plasma cells $\left(\mathrm{CD} 138^{+} \mathrm{B} 220^{\text {low }}\right)$ were sorted from spleen 7 days after NP-KLH immunization. Naive B cells $\left(\mathrm{CD} 20^{+} \mathrm{CD} 27^{-} \mathrm{CD} 38^{\mathrm{lo}}\right)$, memory B cells $\left(\mathrm{CD} 20^{+} \mathrm{CD} 27^{+} \mathrm{CD} 38^{\mathrm{lo}}\right)$ and $\mathrm{GC} \mathrm{B}$ cells $\left(\mathrm{CD} 20^{+} \mathrm{CD} 388^{\mathrm{hi}} \mathrm{CD} 27^{+}\right)$were sorted to $>98 \%$ purity from human tonsils using the indicated antibodies. Tonsillar tissues were collected following informed consent from patients undergoing routine tonsillectomy (Mater Hospital, North Sydney, Australia). Approval for this study was obtained from the human research ethics committees of the St. Vincent's Hospital and Sydney South West Area Health Service, NSW, Australia.

Bone marrow chimeras. To generate 50:50 chimeras, lethally irradiated Ly5.1 mice $(2 \times 5.5 \mathrm{~Gy})$ were reconstituted with a mixture of $50 \%$ Ly5.1 BM and $50 \%$ Prmt $1^{\text {fl }}$ ${ }_{\mathrm{fl}} \mathrm{CD} 23^{\mathrm{Cre} /+}$ or $\mathrm{CD} 23^{\mathrm{Cre} /+}$ BM. Mice were rested for 7-8 weeks before

NP-KLH/alum immunization as described above. For $\mu$ MT chimeras, lethally irradiated Ly5.1 mice $(2 \times 5.5 \mathrm{~Gy})$ were reconstituted with $80 \% \mu \mathrm{MT}$ BM and $20 \%$ Prmt $1^{\text {flffl }}$ ERT2 $^{\mathrm{Cre} /+}$ or ERT2 ${ }^{\mathrm{Cre} /+}$ BM. Mice were rested for 9 weeks and then immunized with NP-KLH in alum. Nine weeks after immunization, mice were treated three times ( 1 dose per day at days 1,2 and 8) with Tamoxifen to induce activation of $\mathrm{Cre}^{40}$, and then at day 10 boosted with NP-KLH in PBS, injected i.p. Mice were bled before immunization to test chimerism by flow cytometry.

Histology, ELISPOT and ELISA. Portions of spleen were frozen in OCT (TissueTek Sakura), and $7 \mu \mathrm{m}$ sections were cut with a microtome (Leica) at $-20^{\circ} \mathrm{C}$ Sections were fixed in ice-cold acetone for $10 \mathrm{~min}$, air-dried, then stained as indicated in the figures with goat anti-mouse IgM conjugated to HRP (Southern Biotech) at 1:200 dilution, biotinylated anti-IgD (clone 1126c; Southern Biotech) at 1:100 dilution, or anti-GL7 (clone GL7; made in-house) at 1:200 dilution. Biotinylated antibodies were revealed using streptavidin alkaline phosphatase (Southern Biotech) at 1:200 dilution. Unlabelled antibody was detected with anti-rat kappa HRP (Southern Biotech) at 1:200 dilution. Staining was visualised with an AEC substrate kit (Vector Laboratories) and Vector Blue substrate kit (Vector Laboratories $^{41}$ and slides were mounted using Aqua Polymount (Polysciences, Inc.). ASC and serum antibody titres were analyzed by ELISPOT and ELISA, respectively ${ }^{41}$. For ELISA, at the times indicated blood was collected and serum separated. 96-well plates were coated with $20 \mu \mathrm{g} \mathrm{ml}^{-1} \mathrm{NP}_{13}$-BSA (conjugated in-house), and diluted serum was incubated for at least $20 \mathrm{~h}$ at room temperature. NP-specific IgG1 was 
detected with goat anti-mouse IgG1-HRP (Southern Biotech) at 1:500 dilution and visualized with ABTS substrate (2,2-Azinobis [3-ethylbenzthiazoline Sulfonic Acid]; Sigma-Aldrich). For ELISpots, splenocytes were added to a 96-well cellulose ester membrane plate (Millipore) coated with $20 \mu \mathrm{g} \mathrm{ml}^{-1}$ of $\mathrm{NP}_{13}-\mathrm{BSA}$ and incubated for up to $20 \mathrm{~h}$ at $37^{\circ} \mathrm{C}$ and $5-10 \% \mathrm{CO}_{2}$. Anti-NP-specific $\mathrm{IgG}_{1}, \mathrm{IgM}$ or IgG were revealed using goat anti-mouse antibodies conjugated to HRP at 1:500 dilution (all from Southern Biotech), and visualized with substrate AEC (3-amino-9ethyl carbazole; Sigma-Aldrich). Spots were counted using an automated reader (AID ELISpot Reader System, software version 4).

Cell lysates and western blot. Mouse and human B cells were lysed on ice for 30 min in Ex-250 lysis buffer (20 mM Hepes, pH 7.5, $250 \mathrm{mM} \mathrm{NaCl}, 0.5 \mathrm{mM} \mathrm{MgCl}_{2}$, $0.5 \% \mathrm{NP}-40$, complete protease inhibitors (Roche) and $500 \mu \mathrm{M}$ sodium orthovanadate). Lysates were centrifuged for $10 \mathrm{~min}$ at $1000 \times \mathrm{g}$, and the supernatant was further diluted with Ex-00 (20 mM Hepes, pH 7.5, $0.5 \mathrm{mM} \mathrm{MgCl}_{2}, 0.5 \%$ NP-40) to obtain a final concentration of $150 \mathrm{mM} \mathrm{NaCl}$. This was centrifuged for $20 \mathrm{~min}$ at $20,000 \times \mathrm{g}$. Human tonsil naive $\left(\mathrm{CD} 20^{+} \mathrm{CD} 27^{-} \mathrm{CD} 38^{\mathrm{lo}}\right)$, memory $\left(\mathrm{CD} 20^{+} \mathrm{CD} 27^{+} \mathrm{CD} 38^{\mathrm{lo}}\right)$ and $\mathrm{GC}$ $\left(\mathrm{CD} 20^{+} \mathrm{CD} 38^{\text {hi }} \mathrm{CD} 27^{+}\right) \mathrm{B}$ cells were lysed on ice for $30 \mathrm{~min}$ in lysis buffer containing protease/phosphatase inhibitors (1\% NP-40 in $10 \mathrm{mM}$ Tris-HCL, $150 \mathrm{mM} \mathrm{NaCl}, 0.1 \%$ $\mathrm{NaN}_{3}, \mathrm{pH} 7.8$ ) and centrifuged for $20 \mathrm{~min}$ at $14,000 \mathrm{rpm}$. Lysates were separated by SDS-PAGE and transferred to membranes that were probed with the following antibodies: BCL2 (3F11; BD Biosciences), MCL1 (19C4-15; WEHI), A1 (6D6; WEHI) ${ }^{42}$, Actin (goat polyclonal; Santa Cruz), PRMT1 (rabbit polyclonal; Cell Signalling), phospho-Foxo1 (Ser256, rabbit polyclonal; Cell Signalling), phospho-PKB (Ser473, rabbit clone 193H12; Cell Signalling), phospho-p44/42 (pERK1/2, Thr202/Tyr204, rabbit polyclonal; Cell Signalling), BCLX (44/Bcl-x; mouse monoclonal; BD); dimethyl-arginine antibody (ASYM24; rabbit polyclonal; Millipore), phosphotyrosine (4G10; Millipore). Western blots were developed using an in-house enhanced chemiluminescence system

B-cell activation. B cells were activated with the following stimuli: CD40L (1:1000 membrane preparation from Sf21 cells ${ }^{22}$ ) in the presence of recombinant mouse IL-4 (10 ng ml ${ }^{-1}$; R\&D Systems) and IL-5 (5 $\mathrm{ng} \mathrm{ml}^{-1}$; R\&D Systems); F( $\left(\mathrm{ab}^{\prime}\right)_{2}$ antiIgM antibody $\left(20 \mu \mathrm{g} \mathrm{ml}^{-1}\right.$; Jackson ImmunoResearch); or LPS $\left(25 \mu \mathrm{g} \mathrm{ml}^{-1}\right.$; Difco) for the indicated times. Pancaspase inhibitor Q-VD (MP Biomedicals) was used at a final concentration of $10 \mu \mathrm{M}$. Human B cells were stimulated with $100 \mathrm{ng} \mathrm{ml}^{-1}$ of Mega CD40L (Enzo) in the presence of $50 \mathrm{ng} \mathrm{ml}^{-1}$ recombinant human IL-4 (Peprotech)

In vivo methylation assay. Naive or activated B cells were incubated for $30 \mathrm{~min}$ in RPMI 1640 complete medium without methionine (Gibco) containing $20 \mu \mathrm{g} \mathrm{ml}^{-1}$ chloramphenicol and $100 \mu \mathrm{g} \mathrm{ml}^{-1}$ cycloheximide (Sigma-Aldrich), after which the cells were labelled with $10 \mu \mathrm{Ci} \mathrm{ml}^{-1}$ of L-[methyl-3H] methionine ${ }^{14}$. The cells were incubated for an additional $3 \mathrm{~h}$ in the presence of the methyl group donor and the same protein synthesis inhibitors. The cells were lysed, equal samples loaded on a gel and blotted onto a nitrocellulose membrane. Methionine incorporation was determined by autoradiography.

Statistical analyses. Data sets were compared for significant differences using appropriate tests and as indicated in the relevant figure legends. Variances between groups that were being statistically compared were similar.

Data availability. The data that support the findings of this study are available from the corresponding author upon request.

Received: 4 August 2016 Accepted: 11 August 2017

Published online: 12 October 2017

\section{References}

1. Bedford, M. T. \& Richard, S. Arginine methylation an emerging regulator of protein function. Mol. Cell 18, 263-272 (2005).

2. Bedford, M. T. \& Clarke, S. G. Protein arginine methylation in mammals: who, what, and why. Mol. Cell 33, 1-13 (2009).

3. Blanchet, F., Schurter, B. T. \& Acuto, O. Protein arginine methylation in lymphocyte signaling. Curr. Opin. Immunol. 18, 321-328 (2006).

4. Pawlak, M. R., Scherer, C. A., Chen, J., Roshon, M. J. \& Ruley, H. E. Arginine $\mathrm{N}$-methyltransferase 1 is required for early postimplantation mouse development, but cells deficient in the enzyme are viable. Mol. Cell. Biol. 20, 4859-4869 (2000)

5. Tee, W. W. et al. Prmt5 is essential for early mouse development and acts in the cytoplasm to maintain ES cell pluripotency. Genes Dev. 24, 2772-2777 (2010).

6. Ganesh, L. et al. Protein methyltransferase 2 inhibits NF-kappaB function and promotes apoptosis. Mol. Cell. Biol. 26, 3864-3874 (2006).
7. Neault, M., Mallette, F. A., Vogel, G., Michaud-Levesque, J. \& Richard, S. Ablation of PRMT6 reveals a role as a negative transcriptional regulator of the p53 tumor suppressor. Nucleic Acids Res. 40, 9513-9521 (2012).

8. Swiercz, R., Cheng, D., Kim, D. \& Bedford, M. T. Ribosomal protein rpS2 is hypomethylated in PRMT3-deficient mice. J. Biol. Chem. 282, 16917-16923 (2007).

9. Yadav, N. et al. Specific protein methylation defects and gene expression perturbations in coactivator-associated arginine methyltransferase 1-deficient mice. Proc. Natl Acad. Sci. USA 100, 6464-6468 (2003).

10. Yang, Y. \& Bedford, M. T. Protein arginine methyltransferases and cancer. Nat Rev. Cancer 13, 37-50 (2013).

11. Blanchet, F., Cardona, A., Letimier, F. A., Hershfield, M. S. \& Acuto, O. CD28 costimulatory signal induces protein arginine methylation in T cells. J. Exp. Med. 202, 371-377 (2005).

12. Boisvert, F. M., Rhie, A., Richard, S. \& Doherty, A. J. The GAR motif of 53BP1 is arginine methylated by PRMT1 and is necessary for 53BP1 DNA binding activity. Cell Cycle 4, 1834-1841 (2005).

13. Cheung, N., Chan, L. C., Thompson, A., Cleary, M. L. \& So, C. W. Protein arginine-methyltransferase-dependent oncogenesis. Nat. Cell Biol. 9, 1208-1215 (2007).

14. Infantino, S. et al. Arginine methylation of the B cell antigen receptor promotes differentiation. J. Exp. Med. 207, 711-719 (2010).

15. Koh, C. M. et al. MYC regulates the core pre-mRNA splicing machinery as an essential step in lymphomagenesis. Nature 523, 96-100 (2015).

16. Mowen, K. A., Schurter, B. T., Fathman, J. W., David, M. \& Glimcher, L. H. Arginine methylation of NIP45 modulates cytokine gene expression in effector T lymphocytes. Mol. Cell 15, 559-571 (2004).

17. Sakamaki, J. et al. Arginine methylation of BCL-2 antagonist of cell death (BAD) counteracts its phosphorylation and inactivation by Akt. Proc. Natl Acad. Sci. USA 108, 6085-6090 (2011).

18. Yamagata, K. et al. Arginine methylation of FOXO transcription factors inhibits their phosphorylation by Akt. Mol. Cell 32, 221-231 (2008).

19. Yu, Z., Chen, T., Hebert, J., Li, E. \& Richard, S. A mouse PRMT1 null allele defines an essential role for arginine methylation in genome maintenance and cell proliferation. Mol. Cell. Biol. 29, 2982-2996 (2009).

20. Kwon, K. et al. Instructive role of the transcription factor E2A in early B lymphopoiesis and germinal center B cell development. Immunity 28, 751-762 (2008).

21. Lalor, P. A., Nossal, G. J., Sanderson, R. D. \& McHeyzer-Williams, M. G. Functional and molecular characterization of single, (4-hydroxy-3nitrophenyl)acetyl (NP)-specific, IgG1+B cells from antibody-secreting and memory B cell pathways in the C57BL/6 immune response to NP. Eur. J. Immunol. 22, 3001-3011 (1992).

22. Hasbold, J., Corcoran, L. M., Tarlinton, D. M., Tangye, S. G. \& Hodgkin, P. D Evidence from the generation of immunoglobulin G-secreting cells that stochastic mechanisms regulate lymphocyte differentiation. Nat. Immunol. 5, 55-63 (2004)

23. Pearce, E. L., Poffenberger, M. C., Chang, C. H. \& Jones, R. G. Fueling immunity: insights into metabolism and lymphocyte function. Science 342, 1242454 (2013)

24. Caro-Maldonado, A. et al. Metabolic reprogramming is required for antibody production that is suppressed in anergic but exaggerated in chronically BAFFexposed B cells. J. Immunol. 192, 3626-3636 (2014).

25. Kitamura, D., Roes, J., Kuhn, R. \& Rajewsky, K. A. B cell-deficient mouse by targeted disruption of the membrane exon of the immunoglobulin mu chain gene. Nature 350, 423-426 (1991).

26. Vikstrom, I. et al. Mcl-1 is essential for germinal center formation and B cell memory. Science 330, 1095-1099 (2010).

27. Strasser, A. The role of BH3-only proteins in the immune system. Nat. Rev. Immunol. 5, 189-200 (2005).

28. Dominguez-Sola, D. et al. The FOXO1 transcription factor instructs the germinal center dark zone program. Immunity 43, 1064-1074 (2015).

29. Kuhn, P. et al. Automethylation of CARM1 allows coupling of transcription and mRNA splicing. Nucleic Acids Res. 39, 2717-2726 (2011).

30. Peperzak, V. et al. Mcl-1 is essential for the survival of plasma cells. Nat. Immunol. 14, 290-297 (2013).

31. Sander, S. et al. PI3 kinase and FOXO1 transcription factor activity differentially control B cells in the germinal center light and dark zones. Immunity 43, 1075-1086 (2015).

32. Omori, S. A. et al. Regulation of class-switch recombination and plasma cell differentiation by phosphatidylinositol 3-kinase signaling. Immunity 25, 545-557 (2006).

33. Yu, Z. et al. The MRE11 GAR motif regulates DNA double-strand break processing and ATR activation. Cell Res. 22, 305-320 (2012).

34. Dolezal, E. et al. The BTG2-PRMT1 module limits pre-B cell expansion by regulating the CDK4-Cyclin-D3 complex. Nat. Immunol. 18, 911-920 (2017). 
35. Dhar, S. et al. Loss of the major Type I arginine methyltransferase PRMT1 causes substrate scavenging by other PRMTs. Sci. Rep. 3, 1311 (2013).

36. Zheng, S. et al. Arginine methylation-dependent reader-writer interplay governs growth control by E2F-1. Mol. Cell 52, 37-51 (2013).

37. Ying, Z. et al. Histone arginine methylation by PRMT7 controls germinal center formation via regulating Bcl6 transcription. J. Immunol. 195, 1538-1547 (2015).

38. Hata, K. et al. Differential regulation of T-cell dependent and T-cell independent antibody responses through arginine methyltransferase PRMT1 in vivo. FEBS Lett. 590, 1200-1210 (2016).

39. Belz, G. T., Xie, W., Altman, J. D. \& Doherty, P. C. A previously unrecognized $\mathrm{H}-2 \mathrm{D}(\mathrm{b})$-restricted peptide prominent in the primary influenza A virus-specific CD8(+) T-cell response is much less apparent following secondary challenge. J. Virol. 74, 3486-3493 (2000).

40. Good-Jacobson, K. L., O’Donnell, K., Belz, G. T., Nutt, S. L. \& Tarlinton, D. M. $\mathrm{c}-\mathrm{Myb}$ is required for plasma cell migration to bone marrow after immunization or infection. J. Exp. Med. 212, 1001-1009 (2015).

41. Zotos, D. et al. IL-21 regulates germinal center B cell differentiation and proliferation through a B cell-intrinsic mechanism. J. Exp. Med. 207, 365-378 (2010).

42. Lang, M. J. et al. Characterisation of a novel A1-specific monoclonal antibody. Cell Death Dis. 5, e1553 (2014).

\section{Acknowledgements}

We thank members of the Tarlinton lab for critical review of the manuscript, discussion and general technical assistance. This work is supported by a National Health and Medical Research Council (NHMRC) Australia program grant to D.T. and G.B. (1054925). S.I. was supported by a DRFG Fellowship, D.T. by an NHMRC Research Fellowship and G.B. by an Australian Research Council Future Fellowship. This work was made possible through Victorian State Government Operational Infrastructure Support and Australian Government NHMRC IRIISS

\section{Author contributions}

S.I. and D.T. designed the research; S.I., A.L. and K.O.D. performed experiments and analyzed the data with D.T.; V.B., D.T.A., M.E., S.R., S.G.T., F.M. and G.B. provided reagents, resources and intellectual input; S.I. and D.T. wrote the manuscript, which was edited by all authors.

\section{Additional information}

Supplementary Information accompanies this paper at doi:10.1038/s41467-017-01009-1.

Competing interests: The authors declare no competing financial interests.

Reprints and permission information is available online at http://npg.nature.com/ reprintsandpermissions/

Publisher's note: Springer Nature remains neutral with regard to jurisdictional claims in published maps and institutional affiliations.

(c) (i) Open Access This article is licensed under a Creative Commons Attribution 4.0 International License, which permits use, sharing, adaptation, distribution and reproduction in any medium or format, as long as you give appropriate credit to the original author(s) and the source, provide a link to the Creative Commons license, and indicate if changes were made. The images or other third party material in this article are included in the article's Creative Commons license, unless indicated otherwise in a credit line to the material. If material is not included in the article's Creative Commons license and your intended use is not permitted by statutory regulation or exceeds the permitted use, you will need to obtain permission directly from the copyright holder. To view a copy of this license, visit http://creativecommons.org/ licenses/by/4.0/.

(C) The Author(s) 2017 